\title{
BMJ Open Retrospective evaluation of healthcare utilisation and mortality of two post- discharge care programmes in Singapore
}

\author{
Ian Yi Han Ang, ${ }^{\oplus 1}$ Chuen Seng Tan, ${ }^{2,3}$ Milawaty Nurjono, ${ }^{2}$ Xin Quan Tan, ${ }^{1,4}$ \\ Gerald Choon-Huat Koh, ${ }^{2,3}$ Hubertus Johannes Maria Vrijhoef, ${ }^{5,6,7}$ Shermin Tan, 8 \\ Shu Ee Ng, ${ }^{3,9}$ Sue-Anne Toh ${ }^{1}$
}

To cite: Ang IYH, Tan CS, Nurjono M, et al. Retrospective evaluation of healthcare utilisation and mortality of two post-discharge care programmes in Singapore. BMJ Open 2019;9:e027220. doi:10.1136/ bmjopen-2018-027220

- Prepublication history and additional material for this paper are available online. To view these files, please visit the journal online (http://dx.doi. org/10.1136/bmjopen-2018027220).

Received 11 October 2018 Revised 22 March 2019 Accepted 26 March 2019
Check for updates

(C) Author(s) (or their employer(s)) 2019. Re-use permitted under CC BY-NC. No commercial re-use. See rights and permissions. Published by BMJ.

For numbered affiliations see end of article.

Correspondence to Dr lan Yi Han Ang; yha2103@columbia.edu

\section{ABSTRACT}

Objective To evaluate the impact on healthcare utilisation frequencies and charges, and mortality of a programme for frequent hospital utilisers and a programme for patients requiring high acuity post-discharge care as part of an integrated healthcare model.

Design A retrospective quasi-experimental study without randomisation where patients who received post-discharge care interventions were matched 1:1 with unenrolled patients as controls.

Setting The National University Health System (NUHS) Regional Health System (RHS), which was one of six RHS in Singapore, implemented the NUHS RHS Integrated Interventions and Care Extension (NICE) programme for frequent hospital utilisers and the NUHS Transitional Care Programme (NUHS TCP) for high acuity post-discharge care. The programmes were supported by the Ministry of Health in Singapore, which is a city-state nation located in Southeast Asia with a 5.6 million population.

Participants Linked healthcare administrative data, for the time period of January 2013 to December 2016, were extracted for patients enrolled in NICE $(n=554)$ or NUHS TCP ( $n=270)$ from June 2014 to December 2015, and control patients.

Interventions For both programmes, teams conducted follow-up home visits and phone calls to monitor and manage patients' post-discharge.

Primary outcome measures One-year pre- and postenrolment healthcare utilisation frequencies and charges of all-cause inpatient admissions, emergency admissions, emergency department attendances, specialist outpatient clinic (SOC) attendances, total inpatient length of stay and mortality rates were compared.

Results Patients in NICE had lower mortality rate, but higher all-cause inpatient admission, emergency admission and emergency department attendance charges. Patients in NUHS TCP did not have lower mortality rate, but had higher emergency admission and SOC attendance charges.

Conclusions Both NICE and NUHS TCP had no improvements in 1 year healthcare utilisation across various setting and metrics. Singular interventions might not be as impactful in effecting utilisation without an overhauling transformation and restructuring of the hospital and healthcare system.

\section{Strengths and limitations of this study}

- This study used healthcare administrative data from a large consolidated database that covered separate episodes of care across different hospitals linked to each individual, eliminating recall errors that would arise from self-reported healthcare utilisation.

- The use of person-level administrative data allowed for selection of controls matched to each patient, which would otherwise not be possible if the administrative data were aggregated at hospital- or national-level.

- The use of matched controls for comparisons allow for isolating intervention programmes' effects on utilisation frequencies and charges, as it takes into account the regression to the mean that could occur in both groups even without intervention.

- The follow-up period of 1 year allowed for the evaluation of the long-term effects of these large-scale real-world programmes, providing relevant evidence for improving integrated care in Singapore and similar health systems.

- The matching of controls was limited by the available information recorded in the administrative database, and so this quasi-experimental study design may not be considered as rigorous as a randomised control trial.

\section{INTRODUCTION}

With a growing and ageing population, and with increased chronic disease prevalence, there is a rising demand for hospital resources and increasing burden on healthcare systems. ${ }^{12}$ Singapore has seen her population of residents grow from 3.27 million in 2000 to 3.97 million in 2017 , with the percentage of those aged 65 years and above increasing from $7.2 \%$ in 2000 to $13.0 \%$ in $2017 .{ }^{3}$ The number of Singapore citizens aged 65 years and above is projected to further increase to about $25 \%$ by $2030 .{ }^{4}$ In $2017,12.7 \%$ of Singapore's resident population had at least one admission into acute hospital, with the percentage for those aged 65 years and above 
higher at over $34 \% .^{5}$ With finite healthcare resources, averting avoidable hospital utilisation is an opportunity to improve quality of care and optimise healthcare system resources.

Frequent readmissions to hospital might occur as a result of multiple factors. At the patient-level, low health literacy, ${ }^{6}$ poor social support ${ }^{78}$ or low socio-economical status, ${ }^{7}$ are contributing factors. At the system-level, challenges include unresolved medical issues at discharge ${ }^{9}$ lack of an appropriate care plan ${ }^{7}$ and lack of coordination between different care providers and services. ${ }^{10}$ Frequent readmissions add to psychological distress on top of the financial strain on both patients and the healthcare system. ${ }^{7}$ Some of these readmissions, however, may be preventable if intervention programmes and operations structures are in place to ensure smooth care transitions and that patients are well-cared for in the community after being discharged. Follow-up home visits ${ }^{11} 12$ and follow-up phone calls ${ }^{11}$ to monitor and manage patients post-discharge, as well as a combination of these with case management in an integrated healthcare model, ${ }^{13-16}$ have all been found to be effective in reducing hospital utilisation.

The Regional Health Systems (RHSs) in Singapore were designed to integrate hospitals with primary and community care partners within a geographical region. Although patients in Singapore are not empanelled and have the freedom to use services from different healthcare providers across different RHSs, previous research has found that less than $10 \%$ of patients have cross-utilisation across different hospitals. ${ }^{17}$ Before 2017, the National University Health System (NUHS) RHS was one of six RHS in Singapore, with National University Hospital (NUH) as the main acute hospital; in 2017, the NUHS RHS underwent a merger with the JurongHealth RHS to form one of three larger RHS in Singapore. NUH was one of the two national hospitals providing complex tertiary care in Singapore, and served over 400000 patients per year. ${ }^{17}$ With the goal of improving post-discharge care, anchoring care in the community and reducing healthcare utilisation, two programmes were launched in 2014: (1) NUHS-RHS Integrated Interventions and Care Extension (NICE) programme and (2) NUHS Transitional Care Programme (NUHS TCP).

The overall objective of both programmes was to facilitate the safe transition from acute hospital to the home of patients, and specifically with the aims to: (1) reduce inpatient admissions and emergency department attendances, (2) reduce total inpatient length of stay (LOS) and (3) reduce cost of care per patient. The NICE programme targeted patients with frequent hospital admissions, frequent hospital utilisers, who had three or more inpatient acute hospital admissions within 1 year. ${ }^{17}{ }^{18}$ Despite being a small percentage of the population, frequent hospital utilisers incur a large proportion of healthcare costs. ${ }^{17}$ 19-22 In 2013, within NUHS RHS, frequent hospital utilisers constituted only $1 \%$ of all patients yet generated about $27 \%$ of all inpatient episodes. ${ }^{17}$ NUHS
TCP targeted patients who were fit for discharge but had a high risk of readmission as they still required high acuity post-discharge care and/or were home-bound with mobility issues limiting access to such post-discharge care.

The aim of the current study was to evaluate if the NICE programme and NUHS TCP had an impact in reducing healthcare utilisation frequencies and charges, and mortality.

\section{METHODS}

\section{Study design}

This retrospective quasi-experimental study used data from the Integrated Population Health Management (PHM) database from the National Healthcare Group Health Services \& Outcomes Research department. The Integrated PHM database contains data from NUH and three of other six major public acute hospitals in Singapore (Ng Teng Fong General Hospital, Alexandra Hospital and Tan Tock Seng Hospital), and includes data from over 2.3 million individuals.

One-year pre- and post-enrolment healthcare utilisation data from all four hospitals were extracted from the database for the time period of January 2013 to December 2016. The extracted data were for patients enroled in the NICE programme or NUHS TCP from June 2014 to December 2015, and also for potential controls that had at least one all-cause inpatient admission - includes emergency admissions - in NUH over the same period. This study was a component of a larger mixed-methods study to evaluate the process and outcome measures of the NICE programme and NUHS TCP. ${ }^{23}$

\section{Patient and public involvement}

Patients and the public were not involved in the designing or conducting of this study.

\section{Setting}

Singapore is a city-state nation located in Southeast Asia with a total population of 5.6 million, of which over 3.9 million are citizens and permanent residents. ${ }^{24}$ The population has an ethnic composition of $74.1 \%$ Chinese, $13.4 \%$ Malays, $9.2 \%$ Indians and $3.3 \%$ Others, ${ }^{25}$ and a life expectancy of 82.9 years. ${ }^{24}$ For the time period from which the healthcare utilisation data were extracted (January 2013 to December 2016), NUHS RHS was one of six RHS in Singapore. The funding for the NICE programme and NUHS TCP was supported by the Ministry of Health as two of its six nation-wide priority areas, covering the management of frequent hospital utilisers and the timely discharge from acute hospitals through transitional care, respectively.

\section{Intervention}

For both the NICE programme and NUHS TCP, there were variations in work processes and outputs due to the profiles of patients served, but in general they had similar 
Table 1 Similarities and differences between the NUHS RHS Integrated Interventions and Care Extension (NICE) programme and NUHS Transitional Care Programme (NUHS TCP)

\begin{tabular}{ll}
\hline NICE programme & NUHS TCP \\
$\begin{array}{l}\text { Enrolled patients with three or more inpatient admissions } \\
\text { within a year }\end{array}$ & $\begin{array}{l}\text { Enrolled patients who required high acuity post-discharge } \\
\text { care and/or were home-bound with mobility issues }\end{array}$ \\
$\begin{array}{l}\text { Patients were enrolled in programme for up to 1 year post- } \\
\text { discharge from hospital }\end{array}$ & $\begin{array}{l}\text { Patients were enrolled in programme for up to 3 months } \\
\text { post-discharge from hospital }\end{array}$ \\
Programme could enrol patients who needed specialised & $\begin{array}{l}\text { Programme could enrol patients who needed specialised } \\
\text { care for burns, stroke and heart failure }\end{array}$ \\
care for chronic obstructive pulmonary disease & Programme conducted follow-up home visits and phone calls to monitor and manage patients' post-discharge \\
Programme referred patients to community-based care and services (for example, home nursing, home hospice, outpatient \\
clinic, social workers and corporate volunteers)
\end{tabular}

NUHS, National University Health System.

objectives and workflows (table 1). For example, each of the programmes had teams conducting follow-up home visits and phone calls to monitor and manage patients' post-discharge. Patients were referred to community-based care and services (for example, home nursing, home hospice, outpatient clinic, social workers and corporate volunteers) when necessary and appropriate. However, both programmes had their unique enrolment criteria. Patients with cancer enroled in the NICE programme $(n=87)$ or NUHS TCP $(n=30)$ were not included in this study, as these patients had a high post-enrolment mortality rate (over 65\%). Additionally, cancer diagnosis information was not available in the Integrated PHM database and so potential control patients could not be appropriately selected to match on cancer types.

\section{NICE programme}

Patients with three or more inpatient admissions within a year and who had associated risk factors for frequent readmission such as functional decline, cognitive impairment and multiple comorbidities could be enroled under the NICE programme. Patients were assigned to a team of case managers who customised the care programme based on the needs of the patients and caregivers. Case management commenced during the inpatient episode and could continue for up to a year post-discharge from hospital, after which, a proper handover process could be carried out to the next healthcare provider to ensure continuity of care.

\section{NUHS TCP}

Patients who required high acuity post-discharge care and/or were home-bound with mobility issues but had an identified caregiver could be enroled under the NUHS TCP. Each patient was assigned to a care team led by a transitional care nurse. Patients were enroled for a post-discharge period of up to 3 months, and services included medical, nursing, rehabilitative and psycho-social support to meet the needs of the patients and caregivers.

\section{Population}

Four groups of patients were generated for comparisons: two intervention and two control groups. Patients enroled in the NICE programme and NUHS TCP from June 2014 to December 2015 were in the intervention groups, and these patients were matched to controls who were patients with at least one admission at NUH but not enroled in either programmes. Matching was conducted separately for the NICE programme and NUHS TCP, with one matched control for every intervention patient selected from the same pool of 50855 potential controls by propensity score matching (detailed below).

\section{Outcomes}

Healthcare utilisation frequencies in the metrics of all-cause inpatient admission, emergency admissions, emergency department attendances, specialist outpatient clinic (SOC) attendances, LOS and the healthcare charges in the metrics of the full gross bill amounts from all-cause inpatient admission, emergency admissions, emergency department attendances and SOC attendances, were calculated for the 1 year period before and after the point of enrolment, which was usually at the end of an admission. Survival days were calculated by subtracting the point of enrolment from the date of death. Patients who survived beyond 1 year from the point of enrolment was assigned the maximal number of 365 days and were censoring events. Mortality rate for the 1 year period after the point of enrolment (1 year mortality) was also calculated.

For patients in the intervention group, the points of enrolment were actual enrolment dates into the NICE programme or NUHS TCP, which usually occurred when the patients were discharged from an admission. For controls, there was no actual point of enrolment into the intervention (or into a control group like a randomised control trial). Only discharge dates of admissions with at least one bed day in NUH which fell within June 2014 to December 2015 were considered as potential proxy for point of enrolment among the controls, in order to 
mimic the triggering event (ie, an inpatient admission to NUH) necessary for consideration for enrolment into either programmes among patients from the intervention group.

\section{Matching for controls}

To obtain a control for each patient in the intervention groups, we generated a population of potential proxies for point of enrolment that corresponded to the discharge dates of all admissions belonging to patients not in the intervention groups, where the discharge dates occurred between June 2014 and December 2015. Hence, patients who are not in the two intervention groups and have multiple admissions with discharge dates between June 2014 and December 2015 would contribute multiple potential proxies for point of enrolment. Although potential proxies for point of enrolment could belong to the same patient, the number of previous admissions in the 1 year period prior could vary across these potential proxies because they corresponded to discharge dates from different admission episodes. This provided a wide spread of potential proxies for point of enrolment over a period with varying pre-enrolment healthcare utilisation patterns. This approach could provide better match given the variety of patients from the intervention group with different points of enrolment and different pre-enrolment healthcare utilisation patterns. For example, patients could have chosen to be enrolled in the NICE programme after more than three all-cause inpatient admissions within a year, and patients enrolled in the NUHS TCP did not have to meet any criteria of minimum all-cause inpatient admissions a year for enrolment.

Propensity score matching ${ }^{26}$ was used to reduce bias in treatment effect estimates by reducing covariate imbalance between the intervention patients and control patients from quasi-experimental studies. Matching was conducted using the MatchIt package ${ }^{27}$ with R V.3.4.1 to generate a group of matched controls. The approach selected was nearest neighbour matching with a 1:1 ratio, whereby each case (a patient from the intervention group) was matched with the potential control (with a proxy for point of enrolment) with the closest propensity score that was generated from the matching variables used. ${ }^{26}$ The following were the matching variables used to construct the propensity score: age at enrolment, gender, ethnic group (Chinese, Malay, Indian, others), residential housing type (1- or 2-room, 3-room, 4-room, 5-room/executive, private/others; serving as proxy for socio-economical status ${ }^{28}{ }^{29}$ ), comorbidities at enrolment (14 identified from the chronic disease management system $^{30}$ as part of the database set-up: asthma, diabetes, hyperlipidaemia, hypertension, atrial fibrillation, heart failure, congestive heart failure, stroke, chronic obstructive pulmonary disease, chronic kidney disease, coronary heart disease, osteoporosis, spine fracture, hip fracture), (proxy) point of enrolment, and 1 year pre-enrolment all-cause inpatient admissions, emergency admissions, emergency department attendances, SOC attendances, LOS, all-cause inpatient admission charges, emergency admission charges, emergency department attendance charges and SOC attendance charges.

\section{Statistical analysis}

Statistical analysis was conducted using Stata V.14.2 (Stata Corp, College Station, Texas, USA). For count data of all-cause inpatient admissions, emergency admissions, emergency department attendances, SOC attendances and LOS, negative binomial regression was used to model these post-enrolment healthcare utilisation frequencies, adjusting for log-transformed pre-enrolment healthcare utilisation frequencies with a value of 0.5 added to the frequencies (to avoid taking the log of zero values which give invalid values) and propensity score. ${ }^{31}$ The model included an offset term to account for varying follow-up time due to death. ${ }^{31}$ Any clustering effect of different proxies for point of enrolment selected as controls and from the same patient was also accounted for with the clustered sandwich estimator which was used to obtain robust standard errors. The incidence rate ratios (IRRs) of the intervention group to the control group with their corresponding 95\% CI were reported for the NICE programme and NUHS TCP respectively. Wilcoxon signed-rank test was conducted to compare pre- and post-enrolment utilisation frequencies for each type of group (intervention and control groups).

For continuous data of all-cause inpatient admission charges, emergency admission charges, emergency department attendance charges and SOC attendance charges, linear regression was used to model these log-transformed post-enrolment healthcare charges with a value of 0.5 added to the charges (to avoid taking the $\log$ of zero values which give invalid values), adjusting for log-transformed pre-enrolment healthcare charges with a value of 0.5 added to the charges, propensity score and the log-transformed survival days (or follow-up time). Any clustering effect of different proxies for point of enrolment selected as controls and from the same patient was also accounted for with the clustered sandwich estimator. The exponential of beta-coefficients, which will be termed mean ratios (MRs) of the intervention group to the control group, and their corresponding $95 \% \mathrm{CI}$ were reported for the NICE programme and NUHS TCP, respectively.

For 1 year mortality, Cox proportional hazard regression analysis was performed, adjusting for propensity score, and any clustering effect of different proxies for point of enrolment selected as controls and from the same patient was accounted for with the clustered sandwich estimator. The hazard ratios (HRs) of the intervention group to the control group with their corresponding 95\% CI were reported for the NICE programme and NUHS TCP, respectively.

Additional analyses were conducted to test for the presence of interaction effects between the intervention and 
sociodemographical variables. The age group variable was dichotomised into patients who were aged 60 years and above ( $\geq 60$ years), and those who were aged below 60 years $(<60$ years). The residential housing type was used as proxy for socio-economical status ${ }^{28} 29$ with five categories: 1- or 2-room, 3-room, 4-room, 5-room/executive and private/others. The sociodemographical variables (gender, age group and residential housing type) were added separately into the regression models for healthcare utilisation frequencies and charges with their corresponding interaction with the intervention variable. This allowed us to assess whether the sociodemographical variable could be an effect modifier in the association of the intervention with healthcare utilisation frequencies and charges. If the interaction term was significant, the intervention effect for each category of the sociodemographical variable was calculated and presented.

\section{RESULTS}

\section{NICE programme}

Propensity score matching identified 554 controls for the 554 intervention patients enroled in the NICE programme. Among the 554 controls, there were 500 unique control patients, where 456 control patients contributed one unique proxy for point of enrolment, 35 control patients contributed two unique proxies each, eight control patients contributed three unique proxies each, one control patient contributed four unique proxies each and each of these 554 unique proxies was matched to a unique intervention patient. Visual review of the propensity score distribution plots for cases, matched controls and unmatched control pool of patients indicate the close distribution of propensity scores of cases and matched controls (online supplementary data 1 ). Demographical information and pre-enrolment hospital utilisation frequencies and charges of the two groups are presented in table 2.

No significant differences were observed between the intervention patients enroled in the NICE programme and control patients for post-enrolment all-cause inpatient admission charges, emergency admission charges, emergency department attendance charges, SOC attendance charges and LOS (table 3). The IRR for emergency admissions (IRR $=1.15$, 95\% CI 0.99 to 1.33 ) and SOC attendances (IRR $=0.90,95 \%$ CI 0.80 to 1.01 ) both did not reach statistical significance. Significantly higher all-cause inpatient admission charges $(\mathrm{MR}=2.38,95 \% \mathrm{CI}$ 1.44 to 3.92$)$, emergency admission charges $(\mathrm{MR}=2.71$, 95\% CI 1.60 to 4.58$)$ and emergency department attendance charges (MR=2.17, 95\% CI 1.50 to 3.13) among intervention patients were observed when compared with the control patients. SOC attendance charges among intervention patients were not statistical different from the control patients (MR=1.31, 95\% CI 0.96 to 1.79 ).

For all-cause inpatient admission charges, emergency admission charges and emergency department attendance charges, the interaction term between intervention status
Table 2 Demographical information and pre-enrolment healthcare utilisation and costs of patients enrolled in the NICE programme (intervention group) and their matched controls (control group)

\begin{tabular}{|c|c|c|}
\hline & $\begin{array}{l}\text { Intervention } \\
n=554\end{array}$ & Control $n=554$ \\
\hline Age, mean (SD) & $76.6(11.8)$ & $77.7(11.6)$ \\
\hline \multicolumn{3}{|l|}{ Gender, n (\%) } \\
\hline Female & $251(45.3 \%)$ & 275 (49.6\%) \\
\hline Male & $303(54.7 \%)$ & $279(50.4 \%)$ \\
\hline \multicolumn{3}{|l|}{ Race, n (\%) } \\
\hline Chinese & $394(71.1 \%)$ & $379(68.4 \%)$ \\
\hline Malay & $90(16.3 \%)$ & $111(20 \%)$ \\
\hline Indian & $45(8.1 \%)$ & $50(90 . \%)$ \\
\hline Others & 25 (4.5\%) & $14(2.5 \%)$ \\
\hline \multicolumn{3}{|l|}{ Housing type, n (\%) } \\
\hline 1- or 2-bedroom & $33(6.0 \%)$ & $37(6.7 \%)$ \\
\hline 3-bedroom & $120(21.7 \%)$ & $117(21.1 \%)$ \\
\hline 4-bedroom & $204(36.8 \%)$ & $193(34.8 \%)$ \\
\hline 5-bedroom/executive & $108(19.5 \%)$ & $117(21.1 \%)$ \\
\hline Private/others & $89(16.1 \%)$ & $90(16.3 \%)$ \\
\hline \multicolumn{3}{|l|}{ Comorbidities, n (\%) } \\
\hline Asthma & $103(18.6 \%)$ & $93(16.8 \%)$ \\
\hline Diabetes & 319 (57.6\%) & $329(59.4 \%)$ \\
\hline Hyperlipidaemia & $472(85.2 \%)$ & $473(85.4 \%)$ \\
\hline Hypertension & $463(83.6 \%)$ & $470(84.8 \%)$ \\
\hline Atrial fibrillation & $137(24.7 \%)$ & $136(24.5 \%)$ \\
\hline Heart failure & $190(34.3 \%)$ & $182(32.9 \%)$ \\
\hline Stroke & $186(33.6 \%)$ & $178(32.1 \%)$ \\
\hline $\begin{array}{l}\text { Chronic obstructive } \\
\text { pulmonary disease }\end{array}$ & $171(30.9 \%)$ & 169 (30.5\%) \\
\hline Chronic kidney disease & $338(61.0 \%)$ & $351(63.4 \%)$ \\
\hline Coronary heart disease & $287(51.8 \%)$ & $282(50.9 \%)$ \\
\hline Osteoporosis & $84(15.2 \%)$ & $80(14.4 \%)$ \\
\hline Spine fracture & $60(10.8 \%)$ & $62(11.2 \%)$ \\
\hline Hip fracture & $55(9.9 \%)$ & $59(10.6 \%)$ \\
\hline
\end{tabular}

Pre-enrolment hospital

utilisation frequencies, mean

(SD)

$\begin{array}{lll}\text { All-cause admissions } & 4.46(2.43) & 4.36(3.49) \\ \text { Emergency admissions } & 4.13(2.26) & 3.99(3.34) \\ \begin{array}{l}\text { Emergency department } \\ \text { attendances }\end{array} & 4.67(2.93) & 4.50(4.92) \\ \text { SOC attendances } & 6.90(6.53) & 6.92(7.96) \\ \text { All-cause admissions LOS } & 31.04(24.85) & 32.49(34.30)\end{array}$

Pre-enrolment healthcare

utilisation charges (\$), mean

(SD)

\begin{tabular}{lll}
$\begin{array}{l}\text { All-cause admission } \\
\text { charges }\end{array}$ & $29199(29791)$ & $30420(34$ 953) \\
$\begin{array}{l}\text { Emergency admission } \\
\text { charges }\end{array}$ & $26542(27120)$ & $28213(33595)$ \\
\hline
\end{tabular}

Continued 


\begin{tabular}{lll} 
Table 2 Continued & & \\
& $\begin{array}{l}\text { Intervention } \\
\mathbf{n}=\mathbf{5 5 4}\end{array}$ & Control $\mathbf{n}=\mathbf{5 5 4}$ \\
\hline $\begin{array}{l}\text { Emergency department } \\
\text { attendance charges }\end{array}$ & $1690(1021)$ & $1624(1510)$ \\
SOC attendance charges & $953(971)$ & $966(2167)$ \\
\hline
\end{tabular}

LOS, length of stay; NICE, NUHS RHS Integrated Interventions and Care Extension; SOC, specialist outpatient clinic.

and gender was significant (online supplementary data 2). Female intervention patients had significantly higher all-cause inpatient admission charges $(\mathrm{MR}=3.99,95 \% \mathrm{CI}$ 1.87 to 8.52 ), emergency admission charges $(\mathrm{MR}=5.47$, 95\% CI 2.50 to 12.00 ) and emergency department attendance charges $(\mathrm{MR}=3.39,95 \%$ CI 1.95 to 5.89 ) than the female control patients.

Within intervention patients and within control patients, the post-enrolment all-cause inpatient admissions, emergency admissions, emergency department attendances and LOS were significantly lower than the pre-enrolment counterparts, indicating regression to the mean. The post-enrolment SOC was significantly higher than the pre-enrolment SOC among the control patients only. The mortality hazard of the intervention patients was 26 (95\% CI 5 to 41$)$ per cent lower than the control patients.

\section{NUHS TCP}

Propensity score matching identified 270 controls for the 270 intervention patients enroled in the NUHS TCP. Among the 270 controls, there were 266 unique control patients, where 262 control patients contributed one unique proxy for point of enrolment, four control patients contributed two unique proxies each and each of these 270 unique proxies was matched to a unique intervention patient. Visual review of the propensity score distribution plots for cases, matched controls and unmatched control pool of patients indicate the similar distribution of propensity scores between cases and matched controls (online supplementary data 3). Demographical information and pre-enrolment hospital utilisation frequencies and charges of the two groups are presented in table 4 .

No significant differences were observed between the intervention and control patients for post-enrolment all-cause inpatient admissions, emergency admissions, emergency department attendances, SOC attendances and LOS (table 5). Significantly higher post-enrolment emergency admission charges (MR $=2.64,95 \%$ CI 1.15 to 6.06) and post-enrolment SOC attendance charges $(\mathrm{MR}=4.50,95 \% \mathrm{CI} 2.82$ to 7.18$)$, among intervention

Table 3 Post-enrolment healthcare utilisation and costs, and the mortality rate, as number and percentage (\%) of deaths in 1 year post-enrolment for patients enrolled in the NICE (intervention group) and their matched controls (control group), with adjusted incidence rate ratios (IRRs), mean ratios (MRs) and hazard ratio (HRs), of intervention group to control group, and their corresponding $95 \% \mathrm{Cls}$

\begin{tabular}{|c|c|c|c|c|}
\hline & Intervention & Control & $\begin{array}{l}\text { Adjusted effect size } \\
\text { estimate }\end{array}$ & $95 \% \mathrm{Cl}$ \\
\hline $\begin{array}{l}\text { Healthcare utilisation frequencies, } \\
\text { mean (SD) }\end{array}$ & & & $\mathrm{IRR}^{*}$ & \\
\hline All-cause admissions & $3.05(3.81)$ & $2.34(2.92)$ & 1.11 & 0.97 to 1.28 \\
\hline Emergency admissions & $2.80(3.71)$ & $2.04(2.73)$ & 1.15 & 0.99 to 1.33 \\
\hline $\begin{array}{l}\text { Emergency department } \\
\text { attendances }\end{array}$ & $3.23(4.30)$ & $2.61(4.92)$ & 1.08 & 0.92 to 1.28 \\
\hline SOC attendances & $6.45(6.90)$ & $6.19(7.28)$ & 0.90 & 0.80 to 1.01 \\
\hline All-cause admissions LOS & $19.43(26.59)$ & $17.29(29.07)$ & 0.98 & 0.81 to 1.19 \\
\hline $\begin{array}{l}\text { Healthcare utilisation charges (\$), } \\
\text { mean (SD) }\end{array}$ & & & $\mathrm{MR} \dagger$ & \\
\hline All-cause admission charges & $15768(23280)$ & $15229(27$ 129) & 2.38 & 1.44 to 3.92 \\
\hline Emergency admission charges & 14491 (20 998) & $13699(25837)$ & 2.71 & 1.60 to 4.58 \\
\hline $\begin{array}{l}\text { Emergency department } \\
\text { attendance charges }\end{array}$ & $1086(1436)$ & $814(1355)$ & 2.17 & 1.50 to 3.13 \\
\hline \multirow[t]{2}{*}{ SOC attendance charges } & 952 (1031) & $822(1337)$ & 1.31 & 0.96 to 1.79 \\
\hline & & & $\mathrm{HR} \ddagger$ & \\
\hline 1 year mortality, n (\%) & $134(24.2 \%)$ & 169 (30.5\%) & 0.74 & 0.59 to 0.95 \\
\hline
\end{tabular}

*Adjusted for pre-enrolment healthcare utilisation and propensity score.

†Adjusted for pre-enrolment healthcare cost, propensity score and survival days (or follow-up time).

$\ddagger$ Adjusted for propensity score.

LOS, length of stay; NICE, NUHS RHS Integrated Interventions and Care Extension; SOC, specialist outpatient clinic. 
Table 4 Demographical information and pre-enrolment healthcare utilisation and costs of patients enrolled in the NUHS TCP (intervention group) and their matched controls (control group)

\begin{tabular}{|c|c|c|}
\hline & Interventionn $=\mathbf{2 7 0}$ & Control $n=270$ \\
\hline Age, mean (SD) & $72.3(15.6)$ & $73.0(13.4)$ \\
\hline \multicolumn{3}{|l|}{ Gender, n (\%) } \\
\hline Female & 160 (59.3\%) & $165(61.1 \%)$ \\
\hline Male & $110(40.7 \%)$ & 105 (38.9\%) \\
\hline \multicolumn{3}{|l|}{ Race, n (\%) } \\
\hline Chinese & $184(68.2 \%)$ & 187 (69.3\%) \\
\hline Malay & 52 (19.3\%) & $46(17 \%)$ \\
\hline Indian & $21(7.8 \%)$ & $22(8.2 \%)$ \\
\hline Others & $13(4.8 \%)$ & $15(5.6 \%)$ \\
\hline \multicolumn{3}{|l|}{ Housing type, n (\%) } \\
\hline 1- or 2-bedroom & $5(1.9 \%)$ & 7 (2.6\%) \\
\hline 3-bedroom & $48(17.8 \%)$ & $65(24.1 \%)$ \\
\hline 4-bedroom & $104(38.5 \%)$ & $91(33.7 \%)$ \\
\hline 5-bedroom/executive & $62(23 \%)$ & $47(17.4 \%)$ \\
\hline Private/others & $51(18.9 \%)$ & $60(22.2 \%)$ \\
\hline \multicolumn{3}{|l|}{ Comorbidities, n (\%) } \\
\hline Asthma & $22(8.1 \%)$ & $28(10.4 \%)$ \\
\hline Diabetes & $151(55.9 \%)$ & 147 (54.4\%) \\
\hline Hyperlipidaemia & 227 (84.1\%) & $223(82.6 \%)$ \\
\hline Hypertension & $222(82.2 \%)$ & 223 (82.6\%) \\
\hline Atrial fibrillation & $71(26.3 \%)$ & $64(23.7 \%)$ \\
\hline Heart failure & 69 (25.6\%) & $66(24.4 \%)$ \\
\hline Stroke & $113(41.9 \%)$ & $119(44.1 \%)$ \\
\hline $\begin{array}{l}\text { Chronic obstructive } \\
\text { pulmonary disease }\end{array}$ & $9(3.3 \%)$ & $13(4.8 \%)$ \\
\hline $\begin{array}{l}\text { Chronic kidney } \\
\text { disease }\end{array}$ & $142(52.6 \%)$ & $144(53.3 \%)$ \\
\hline $\begin{array}{l}\text { Coronary heart } \\
\text { disease }\end{array}$ & $98(36.3 \%)$ & $100(37.0 \%)$ \\
\hline Osteoporosis & $40(14.8 \%)$ & $50(18.5 \%)$ \\
\hline Spine fracture & 27 (10.0\%) & $30(11.1 \%)$ \\
\hline Hip fracture & $20(7.4 \%)$ & 24 (8.9\%) \\
\hline
\end{tabular}

Pre-enrolment hospital utilisation frequencies, mean (SD)

\begin{tabular}{lll}
\hline $\begin{array}{l}\text { All-cause admissions } \\
\text { Emergency }\end{array}$ & $2.43(1.98)$ & $2.28(1.62)$ \\
$\begin{array}{l}\text { admissions } \\
\begin{array}{l}\text { Emergency } \\
\text { department } \\
\text { attendances }\end{array}\end{array}$ & $2.13(1.65)$ & $2.02(1.49)$ \\
\hline $\begin{array}{l}\text { SOC attendances } \\
\text { All-cause admissions } \\
\text { LOS }\end{array}$ & $24.20(5.78(32.80)$ & $2.15(1.69)$ \\
\hline
\end{tabular}

Pre-enrolment

healthcare utilisation

charges $(\$)$, mean (SD)

\begin{tabular}{lll}
\hline Table 4 Continued & & \\
\hline & Interventionn=270 & Control $\mathbf{n = 2 7 0}$ \\
\hline $\begin{array}{l}\text { All-cause admission } \\
\text { charges }\end{array}$ & $25779(34929)$ & $24936(39216)$ \\
$\begin{array}{l}\text { Emergency admission } \\
\text { charges }\end{array}$ & $23201(32970)$ & $22674(37522)$ \\
$\begin{array}{l}\text { Emergency } \\
\text { department } \\
\text { attendance charges }\end{array}$ & $810(620)$ & $766(613)$ \\
$\begin{array}{l}\text { SOC attendance } \\
\text { charges }\end{array}$ & $713(803)$ & $574(1144)$ \\
\hline
\end{tabular}

LOS, length of stay; NUHS TCP, National University Health System Transitional Care Programme; SOC, specialist outpatient clinic.

patients were observed when compared with the control patients.

For SOC attendances, the interaction term between intervention status and age group was significant (online supplementary data 4 ). Intervention patients that are $\geq 60$ years had a significantly lower SOC attendance rates (IRR $=0.80,95 \%$ CI 0.67 to 0.94$)$ than matched controls that are $\geq 60$ years. The same interaction term was also significant for SOC attendance charges, where both younger and older age groups had a significantly higher SOC attendance charges $(<60: \mathrm{MR}=21.64,95 \%$ CI 9.17 to 51.06 ; $\geq 60$ : $\mathrm{MR}=2.78,95 \% \mathrm{CI} 1.63$ to 4.74$)$ than their respective matched control patients. For LOS, the interaction term between intervention status and gender was significant, where male intervention patients had a significantly higher LOS (IRR=1.73, 95\% CI 1.06 to 2.84) than male control patients. The interaction term between intervention status and housing type was also significant for LOS, where intervention patients living in 3-room housing had significantly lower LOS (IRR $=0.49$, 95\% CI 0.25 to 0.97 ) than control patients living in 3-room housing, and intervention patients living in private/other housing types had significantly higher LOS $(I R R=2.28$, 95\% CI 1.08 to 4.79 ) than control patients living in private/other housing types. Only the interaction term between intervention status and housing type was significant for all-cause admission charges, where intervention patients living in private/other housing types had a significantly higher LOS (MR=10.34, 95\% CI 1.71 to 62.57 ) than control patients living in private/other housing types.

Within intervention patients and within control patients, the post-enrolment all-cause inpatient admissions, emergency admissions, emergency department attendances and LOS were significantly lower than their pre-enrolment counterparts, indicating regression to the mean. Within intervention patients and within control patients, the post-enrolment SOC attendances was significantly higher than the pre-enrolment SOC. The mortality hazard ( $\mathrm{HR}=1.41,95 \%$ CI 0.97 to 2.05 ) was not significantly different between the intervention and control groups. 
Table 5 Post-enrolment healthcare utilisation and costs, and the mortality rate, as number and percentage (\%) of deaths in 1 year post-enrolment for patients enrolled in the NUHS TCP (intervention group) and their matched controls (control group), with adjusted incidence rate ratios (IRRs), mean ratios (MRs) and hazard ratio (HRs), of intervention group to control group, and their corresponding $95 \% \mathrm{Cls}$

\begin{tabular}{|c|c|c|c|c|}
\hline & Intervention & Control & $\begin{array}{l}\text { Adjusted effect size } \\
\text { estimate }\end{array}$ & $95 \% \mathrm{Cl}$ \\
\hline $\begin{array}{l}\text { Healthcare utilisation frequencies, } \\
\text { mean (SD) }\end{array}$ & & & $\mathrm{IRR}^{\star}$ & \\
\hline All-cause admissions & $1.70(2.04)$ & $1.62(2.81)$ & 1.05 & 0.82 to 1.34 \\
\hline Emergency admissions & $1.36(1.74)$ & $1.27(2.49)$ & 1.13 & 0.87 to 1.48 \\
\hline $\begin{array}{l}\text { Emergency department } \\
\text { attendances }\end{array}$ & $1.52(1.90)$ & $1.55(3.36)$ & 1.03 & 0.77 to 1.37 \\
\hline SOC attendances & $6.56(7.05)$ & $6.67(6.81)$ & 0.91 & 0.78 to 1.05 \\
\hline All-cause admissions LOS & $14.53(29.85)$ & $11.94(25.12)$ & 1.10 & 0.76 to 1.61 \\
\hline $\begin{array}{l}\text { Healthcare utilisation charges (\$), } \\
\text { mean (SD) }\end{array}$ & & & $\mathrm{MR} \dagger$ & \\
\hline All-cause admission charges & 14751 (30 312) & $13064(30921)$ & 1.90 & 0.86 to 4.23 \\
\hline Emergency admission charges & 12914 (29 074) & $10375(27$ 165) & 2.64 & 1.15 to 6.06 \\
\hline $\begin{array}{l}\text { Emergency department } \\
\text { attendance charges }\end{array}$ & $493(607)$ & 499 (990) & 1.40 & 0.78 to 2.51 \\
\hline \multirow[t]{2}{*}{ SOC attendance charges } & $1009(1144)$ & $774(1390)$ & 4.50 & 2.82 to 7.18 \\
\hline & & & HR $\ddagger$ & \\
\hline $\begin{array}{l}1 \text { year mortality, } \\
\mathrm{n}(\%)\end{array}$ & $67(24.8 \%)$ & $48(17.8 \%)$ & 1.41 & 0.97 to 2.05 \\
\hline
\end{tabular}

${ }^{*}$ Adjusted for pre-enrolment healthcare utilisation and propensity score.

†Adjusted for pre-enrolment healthcare cost, propensity score and survival days (or follow-up time).

$\ddagger$ Adjusted for propensity score.

LOS, length of stay; NUHS TCP, National University Health System Transitional Care Programme, SOC, specialist outpatient clinic.

\section{DISCUSSION}

\section{Principal findings}

The post-enrolment all-cause inpatient admissions, emergency admissions, emergency department attendances, SOC attendances and LOS were not statistically different in patients enroled in the NICE programme or NUHS TCP, when compared with their matched controls. However, the all-cause inpatient admission charges, emergency admission charges and emergency department attendance charges were significantly higher in patients enroled in the NICE programme, and the emergency admission charges and SOC attendance charges were significantly higher in patients enroled in the NUHS TCP, when compared with their matched controls. Female patients enroled in the NICE programme had significantly higher all-cause inpatient admission charges, emergency admission charges and emergency department attendance charges than the female matched control patients. Older patients (aged 60 years and above) enroled in the NUHS TCP had significantly lower SOC attendances but had significantly higher SOC attendance charges, while male patients enroled in the NUHS TCP had significantly higher LOS, compared with their respective matched controls. Patients living in private/other housing types enroled in the NUHS TCP also had significantly longer LOS and thus incurred greater all-cause admission charges than the matched control patients living in private/other housing types. Patients enroled in the NICE programme, of which over $30 \%$ had history of heart failure, had lower mortality than their matched controls, mirroring findings from another study with heart failure patients. ${ }^{13}$

\section{Strengths}

For this study, the follow-up period of 1 year allowed us to evaluate the long-term effects of the programmes. The use of healthcare administrative data avoided recall errors or missing data issues that would arise from self-reported healthcare utilisation, particularly for a long follow-up period. The healthcare administrative data contained patient-level information extracted from a large consolidated database of electronic records from four public hospitals where separate episodes of care across different hospitals were linked to each patient. Although this study did not include data from the other three major public hospitals and all other private acute hospitals in Singapore, patients having an encounter with a specific acute hospital would likely return to the same acute hospital for follow-up care, as previous research has found that less than $10 \%$ of patients have cross-utilisation across different hospitals. ${ }^{17}$ 
The use of patient-level administrative data allowed for selection of matched controls, which would otherwise not be possible if the administrative data was aggregated at hospital- or national-level. Previous evaluation of a transitional home care programme in Singapore ${ }^{32}$ found that post-enrolment SOC attendances rates had increased from pre-enrolment rates, where a lack of a comparison control group limited the attribution of the increased SOC attendances to the intervention programme. ${ }^{33}$ For this current study, the post-enrolment SOC attendances had increased among patients enroled in the NUHS TCP and their matched controls too.

The availability of matched controls allows comparisons to take into account the regression to the mean phenomenon that could occur in both groups even without the intervention. ${ }^{22}{ }^{34}$ Comparison between the intervention and matched control groups allow for the partitioning of the intervention programmes' effects on utilisation frequencies and charges. Post-enrolment all-cause inpatient admissions, emergency admissions, emergency department attendances and LOS all regressed to a lower mean following an acute period of high hospital utilisation pre-enrolment, for patients in both programmes and their matched controls. These findings suggest the importance of a comparator group to assess whether changes before and after an intervention can in fact be attributed to the intervention programme.

\section{Limitations}

The traditional 'gold standard' for assessing an intervention programme would conventionally be to conduct a randomised control trial (RCT). However, as both the NICE programme and NUHS TCP were being rolled out hospital-wide, the operational demand and timelines for implementing these programmes at such a large scale could not allow for a RCT to be conducted. Additionally, the use of retrospective study design for the real-world evaluation of other similar interventions have been previously used ${ }^{323536}$ and recommended. ${ }^{37-39}$ Although patients were not randomised into intervention and control groups, inherent bias from confounding factors was mitigated with matching. However, the matching of controls was limited to only information that was recorded and available in administrative databases. Ambulation status and availability of a caregiver at home were part of enrolment criteria for NUHS TCP, but this information was not available for potential controls to be matched on. Even though intervention patients were matched with control patients on comorbidities, our matching was limited in not matching on the diagnoses and reasons for admissions, as well as the specific post-discharge care needs. Additionally, there was a possibility that there were potentially other intervention programmes which some patients were exposed to but such scenarios were not possible to track and account for.

The NICE programme and NUHS TCP each catered to a variety of patient profiles and disease complexities.
The variability in patient needs within the programmes could potentially lead to implementation inconsistencies with care provided by different teams, particularly when the programmes implemented in the real-world evolve organically with time. Based on the evaluation findings of other similar interventions, and earlier pilot or equivalent versions by other health systems in Singapore, NUHS TCP was expected to reduce the rates of overall all-cause inpatient admissions, ${ }^{13141640}$ emergency admissions ${ }^{41}$ and emergency department attendances, ${ }^{41}$ and also reduce all-cause inpatient admission charges, ${ }^{1340}$ even if LOS was not expected to improve. ${ }^{41}$ However, these previous interventions were applied to selective patient populations of elderly above 65 years of age, with heart failure, and/ or with chronic obstructive pulmonary disease, whereas NUHS TCP cared for a more heterogeneous group of patients.

\section{Implications for clinicians and policymakers}

The lack of reductions in all-cause inpatient admissions, emergency admissions, emergency department attendances, SOC attendances and LOS for patients in the NICE programme was not unexpected. Previous research on similar large-scale post-discharge care efforts targeting frequent hospital utilisers, ${ }^{42}{ }^{43}$ have similarly found limited impact of the interventions within such timeframes. This could be due to the fact that frequent hospital utilisers are a unique group of patients experiencing an extreme acute period of high medical need. Previous research has also demonstrated the regression to the mean phenomenon, with hospital utilisation dropping in the following year after a year of frequent hospital admissions. ${ }^{22}{ }^{34}$ Any intervention implemented would thus have to bring about additional benefits beyond this decrease from the regression to the mean. The intervention could thus be more effective if selectively applied to patients assessed to have better prognosis but at risk to continue as frequent hospital utilisers, such as patients who are persistent high utilisers. ${ }^{44-46}$ With close to $30 \%$ of these frequent hospital utilisers (and their matched controls) having less than 1 year of survival, there might be a limit to what can be done to intervene and reverse the course of illness. If these patients could be accurately identified, tailored programmes could instead focus on end-of-life palliative care and management.

The NICE programme and NUHS TCP might be considered large multi-disciplinary interventions, but at their cores, the healthcare services provided as part of these interventions were still centralised within hospital-based teams. The traditional hospital, as we know it today, could be considered to be insufficient in meeting the needs of patients with chronic diseases and multiple comorbidities in the community. ${ }^{47}$ Singular intervention-based adjustments to the existing system hence might not be as impactful in effecting change without an overhauling transformation and restructuring of the public hospitals and healthcare system. In Singapore, there are about 
1700 private primary care physician clinics that cover about $80 \%$ of the total primary care demand ${ }^{48}$ but handle about $60 \%$ of the chronic disease-related attendances in primary care. ${ }^{49}$ The public hospitals can foster stronger partnerships with private primary care physicians to have integrative co-management of patients post-discharge, which would help facilitate shifting from care in hospital to care based in the community and even homes for patients.

\section{Unanswered questions and future research}

The higher costs incurred by the programmes could potentially be due to increased case-finding, ${ }^{50}{ }^{51}$ with close monitoring by case managers in the programmes leading to uncovering of previously undetected problems and directing of patients for further assessment and treatment. Such case finding, and increased further assessments and treatments might also occur more with certain sociodemographical characteristics of the patient population, whereby the younger, female, and more well-off patients are more receptive to take follow-up action, and thus have higher healthcare utilisation. Increased case-finding could also explain the improved mortality, as patients may potentially have returned to the acute hospital in time and received additional medical procedures that contributed to the patients' survival, but not avert higher costs. It should be noted that charges assessed in this study did not include the additional costs incurred to run the NICE programme and NUHS TCP. Future cost-benefit analysis could be conducted to determine if the decrease in mortality for patients enrolled in the NICE programme outweighs the cost to run the programme and the increased healthcare costs.

There is also a crucial need for qualitative implementation fidelity evaluation work set a prori in order to further interpret the findings from healthcare utilisation frequencies and charges outcomes research pertaining to specific programmes. Additionally, evaluation studies should shift beyond just healthcare utilisation frequencies and charges outcomes, and focus instead on outcomes of patients' health confidence, quality of life and quality of care received ${ }^{52}$ This is particularly important when evaluating programmes in their early stages, and determining if they have achieved their objectives. Future work should also explore longer follow-up duration and continue through more mature stages of a programme. Such evaluation studies are important to help inform hospital administrators and policymakers on how to refine these programmes and any other similar efforts towards more integrated care.

\section{Author affiliations}

${ }^{1}$ Regional Health System Planning Office, National University Health System, Singapore

${ }^{2}$ Saw Swee Hock School of Public Health, National University of Singapore, Singapore

${ }^{3}$ National University Singapore Yong Loo Lin School of Medicine, Singapore

${ }^{4}$ National University Singapore Saw Swee Hock School of Public Health, Singapore
${ }^{5}$ Department of Patient and Care, University Hospital Maastricht, Maastricht, The Netherlands

${ }^{6}$ Vrije Universiteit Brussels, Brussels, Belgium

${ }^{7}$ Panaxea b.v., Amsterdam, The Netherlands

${ }^{8}$ Department of Palliative Medicine and Community Transformation Office, Woodlands Health Campus, Singapore

${ }^{9}$ University Medicine Cluster, National University Health System, Singapore

Acknowledgements We would like to thank Joanne Yoong, Sucitro Dwijayana Sidharta, Xin Ya Lim, Nabilah Rahman, and Sheryl Ng for their advice for this study. We would also like to thank Kiok Liang Teow for providing and facilitating the access to the Integrated PHM database, as well as Kah Mun Foo and Brandon Chong for serving as the data intermediaries for this study.

Contributors HJMV and SAT initiated and conceptualised the study. IYHA and CST developed the analysis approach, and MN, XQT, GK, ST and SAT provided feedback for the refinement of the analysis approach. IYHA conducted the data analysis for this study. SEN was the programme director that contributed to the design of the intervention programmes, and provided information on the overall structures of the programmes. IYHA wrote the first draft and the final version of the manuscript. All authors read, edited, provided suggestions for revision and approved the final manuscript.

Funding This work was supported by an internal grant from the NUHS Research Office (grant number NUHSRO/2016/008/R05+5/FY16CF/LOA), the Centre for Health Services and Policy Research (CHSPR) core funding, and the Singapore Ministry of Health's National Medical Research Council Centre Grant Programme (grant number NMRC/CG/C026/2017_NUHS) for Singapore Population Health Improvement Centre (SPHERiC).

Competing interests IYHA, XQT, and SAT are a part of the NUHS RHS strategic planning office, which is involved in the planning and development of programmes under the purview of the NUHS RHS. SEN was the programme director of the NUHS TCP.

Patient consent for publication Not required.

Ethics approval National Healthcare Group - Domain Specific Review Board, Singapore.

Provenance and peer review Not commissioned; externally peer reviewed.

Data sharing statement For access to the data set, a formal request should be sent to the corresponding author. The request will be considered together with the required relevant clearances from the institutions.

Open access This is an open access article distributed in accordance with the Creative Commons Attribution Non Commercial (CC BY-NC 4.0) license, which permits others to distribute, remix, adapt, build upon this work non-commercially, and license their derivative works on different terms, provided the original work is properly cited, appropriate credit is given, any changes made indicated, and the use is non-commercial. See: http://creativecommons.org/licenses/by-nc/4.0/.

\section{REFERENCES}

1. Bodenheimer T, Chen E, Bennett HD. Confronting the growing burden of chronic disease: can the U.S. health care workforce do the job? Health Aff 2009;28:64-74.

2. Vogeli C, Shields AE, Lee TA, et al. Multiple chronic conditions: prevalence, health consequences, and implications for quality, care management, and costs. J Gen Intern Med 2007;22(Suppl 3):391-5.

3. Department of Statistics Singapore. Population Trends, 2018. 2018.

4. National Population and Talent Division SG, Prime Minister's Office. Older Singaporeans to double by 2030. $2016 \mathrm{https} / / / \mathrm{www}$. population.sg/articles/older-singaporeans-to-double-by-2010 (Accessed 26 Feb 2019).

5. Ministry of Health Singapore. Hospital Admission Rates by Age and Sex, 2017p. 2018 https://www.moh.gov.sg/resources-statistics/ healthcare-institution-statistics/hospital-admission-rates-by-ageand-sex/hospital-admission-rates-by-age-and-sex-2017p (Accessed 26 Feb 2019).

6. Mitchell SE, Sadikova E, Jack BW, et al. Health literacy and 30-day postdischarge hospital utilization. J Health Commun 2012;17(Suppl 3):325-38.

7. Longman JM, I Rolfe M, Passey MD, et al. Frequent hospital admission of older people with chronic disease: a cross-sectional survey with telephone follow-up and data linkage. BMC Health Serv Res 2012;12:373. 
8. Longman J, Passey M, Singer J, et al. The role of social isolation in frequent and/or avoidable hospitalisation: rural community-based service providers' perspectives. Aust Health Rev 2013;37:223-31.

9. Moore C, McGinn T, Halm E. Tying up loose ends: discharging patients with unresolved medical issues. Arch Intern Med 2007;167:1305-11.

10. van Walraven C, Seth R, Austin PC, et al. Effect of discharge summary availability during post-discharge visits on hospital readmission. J Gen Intern Med 2002;17:186-92.

11. Wong FK, Chow SK, Chan TM, et al. Comparison of effects between home visits with telephone calls and telephone calls only for transitional discharge support: a randomised controlled trial. Age Ageing 2014;43:91-7.

12. Rytter L, Jakobsen HN, Rønholt $F$, et al. Comprehensive discharge follow-up in patients' homes by GPs and district nurses of elderly patients. A randomized controlled trial. Scand J Prim Health Care 2010;28:146-53.

13. Naylor MD, Brooten DA, Campbell RL, et al. Transitional care of older adults hospitalized with heart failure: a randomized, controlled trial. $J$ Am Geriatr Soc 2004;52:675-84.

14. Wong FK, Ho MM, Yeung S, et al. Effects of a health-social partnership transitional program on hospital readmission: a randomized controlled trial. Soc Sci Med 2011;73:960-9.

15. Poole PJ, Chase B, Frankel A, et al. Case management may reduce length of hospital stay in patients with recurrent admissions for chronic obstructive pulmonary disease. Respirology 2001;6:37-42.

16. Casas A, Troosters T, Garcia-Aymerich J, et al. Integrated care prevents hospitalisations for exacerbations in COPD patients. Eur Respir J 2006;28:123-30.

17. Saxena N, You AX, Zhu Z, et al. Singapore's regional health systems-a data-driven perspective on frequent admitters and cross utilization of healthcare services in three systems. Int $J$ Health Plann Manage 2017;32:36-49.

18. Kirby SE, Dennis SM, Jayasinghe UW, et al. Patient related factors in frequent readmissions: the influence of condition, access to services and patient choice. BMC Health Serv Res 2010;10:216.

19. Cohen SB. The Concentration of Health Care Expenditures and Related Expenses for Costly Medical Conditions, 2012. Statistical Brief (Medical Expenditure Panel Survey (US)). Rockville (MD), 2014.

20. Hines AL, Barrett ML, Jiang HJ, et al. Conditions With the Largest Number of Adult Hospital Readmissions by Payer, 2011: Statistical Brief \#172. Healthcare Cost and Utilization Project (HCUP) Statistical Briefs. Rockville (MD), 2014.

21. Robbins JM, Webb DA. Hospital admission rates for a racially diverse low-income cohort of patients with diabetes: the Urban Diabetes Study. Am J Public Health 2006;96:1260-4.

22. Fuda KK, Immekus R. Frequent users of Massachusetts emergency departments: a statewide analysis. Ann Emerg Med 2006;48:16. e1-8.

23. Nurjono M, Shrestha P, Lee A, et al. Realist evaluation of a complex integrated care programme: protocol for a mixed methods study. BMJ Open 2018;8:e017111.

24. Department of Statistics Singapore. Latest Data. $2017 \mathrm{https} / / \mathrm{www}$. singstat.gov.sg/statistics/latest-data\#16 (Accessed 8 Oct 2018).

25. Department of Statistics Singapore. Census of Population 2010 Statistical Release 1: Demographic Characteristics, Education, Language and Religion. 2011.

26. Stuart EA. Matching methods for causal inference: a review and a look forward. Stat Sci 2010;25:1-21.

27. De H, Imai K, King G, et al. Matchlt: nonparametric preprocessing for parametric causal inference. Journal of Statistical Software 2011;42.

28. Low LL, Wah W, Ng MJ, et al. Housing as a Social Determinant of Health in Singapore and Its Association with Readmission Risk and Increased Utilization of Hospital Services. Front Public Health 2016;4.

29. Rahman N, Wang DD, Ng SH, et al. Processing of Electronic Medical Records for Health Services Research in an Academic Medical Center: Methods and Validation. JMIR Med Inform 2018;6:e10933.
30. Toh MP, Leong HS, Lim BK. Development of a diabetes registry to improve quality of care in the National Healthcare Group in Singapore. Ann Acad Med Singapore 2009;38:546-46.

31. Zheng $\mathrm{H}$, Kimber A, Goodwin VA, et al. A comparison of different ways of including baseline counts in negative binomial models for data from falls prevention trials. Biom $J$ 2018;60:66-78.

32. Low LL, Vasanwala FF, $\mathrm{Ng} \mathrm{LB}$, et al. Effectiveness of a transitional home care program in reducing acute hospital utilization: a quasiexperimental study. BMC Health Serv Res 2015;15:100.

33. Low LL, Tay WY, Tan SY, et al. Transitional Home Care Program Utilizing the Integrated Practice Unit Concept (THC-IPU): Effectiveness in Improving Acute Hospital Utilization. Int J Integr Care 2017;17:5.

34. Roland M, Dusheiko M, Gravelle H, et al. Follow up of people aged 65 and over with a history of emergency admissions: analysis of routine admission data. BMJ 2005;330:289-92.

35. Lindenauer PK, Lagu T, Rothberg MB, et al. Income inequality and 30 day outcomes after acute myocardial infarction, heart failure, and pneumonia: retrospective cohort study. BMJ 2013;346:f521.

36. Bardsley M, Steventon A, Smith J, et al. Evaluating integrated and community-based care: how do we know what works?: Nuffield Trust. 2013

37. Davies A, Ariti C, Georghiou T, et al. Evaluation of complex health and care interventions using retrospective matched control methods: Nuffield Trust. 2015.

38. Cohen AT, Goto S, Schreiber K, et al. Why do we need observational studies of everyday patients in the real-life setting?: Table 1. European Heart Journal Supplements 2015;17:D2-D8.

39. Katkade VB, Sanders KN, Zou KH. Real world data: an opportunity to supplement existing evidence for the use of long-established medicines in health care decision making. J Multidiscip Healthc 2018;11:295-304.

40. Coleman EA, Parry C, Chalmers S, et al. The care transitions intervention: results of a randomized controlled trial. Arch Intern Med 2006;166:1822-8.

41. Wee SL, Loke CK, Liang C, et al. Effectiveness of a national transitional care program in reducing acute care use. J Am Geriatr Soc 2014;62:747-53.

42. Lee KH, Low LL, Allen J, et al. Transitional care for the highest risk patients: findings of a randomised control study. Int $J$ Integr Care 2015;15:e039.

43. Steventon A, Bardsley M, Billings $\mathrm{J}$, et al. The role of matched controls in building an evidence base for hospital-avoidance schemes: a retrospective evaluation. Health Serv Res 2012;47:1679-98.

44. Hwang W, LaClair M, Camacho F, et al. Persistent high utilization in a privately insured population. Am J Manag Care 2015;21:309-16.

45. Bottle A, Aylin P, Majeed A. Identifying patients at high risk of emergency hospital admissions: a logistic regression analysis. $J R$ Soc Med 2006;99:406-14.

46. Low LL, Liu N, Lee KH, et al. FAM-FACE-SG: a score for risk stratification of frequent hospital admitters. BMC Med Inform Decis Mak 2017:17:35

47. Darch R. "Reinventing the hospital", Nuffield Trust guest comment. 2018 https://www.nuffieldtrust.org.uk/news-item/reinventing-thehospital\#anchor-institutions (Accessed 8 Oct 2018).

48. Government of Singapore. Primary Healthcare Services. 2018 https://www.moh.gov.sg/our-healthcare-system/healthcare-servicesand-facilities/primary-healthcare-services (Accessed 28 Jan 2019).

49. Health Information Division $\mathrm{MoH}$, Republic of Singapore. Primary Care Survey 2014. 2014.

50. Sheaff R, Boaden R, Sargent $P$, et al. Impacts of case management for frail elderly people: a qualitative study. $J$ Health Serv Res Policy 2009;14:88-95.

51. Esterman AJ, Ben-Tovim DI. The Australian coordinated care trials: success or failure? The second round of trials may provide more answers. Med J Aust 2002;177:469-70.

52. Lloyd T, Brine R, Pearson R, et al. Briefing: the impact of integrated care teams on hospital use in North East Hampshire and Farnham. 2018. 